\title{
Effects of a Hospitalist Care Model on Mortality of Elderly Patients with Hip Fractures
}

\author{
John A. Batsis, MD1,2 \\ Michael P. Phy, Do $^{3}$ \\ L. Joseph Melton III, $\mathrm{MD}^{4}$ \\ Cathy D. Schleck, Bs ${ }^{5}$ \\ Dirk R. Larson, $\mathrm{ms}^{5}$ \\ Paul M. Huddleston, $\mathrm{MD}^{6}$ \\ Jeanne M. Huddleston, MD $^{7,8}$ \\ ${ }^{1}$ Division of Primary Care Internal Medicine, Mayo \\ Clinic College of Medicine, Rochester, Minnesota \\ ${ }^{2}$ Mayo School of Graduate Medical Education, \\ Mayo Clinic College of Medicine, Rochester, Min- \\ nesota \\ ${ }^{3}$ Department of Medicine, Texas Tech University \\ Health Sciences Center, Lubbock, Texas \\ ${ }^{4}$ Division of Epidemiology, Mayo Clinic College of \\ Medicine, Rochester, Minnesota \\ ${ }^{5}$ Division of Biostatistics, Mayo Clinic College of \\ Medicine, Rochester, Minnesota \\ ${ }^{6}$ Department of Orthopedic Surgery, Mayo Clinic \\ College of Medicine, Rochester, Minnesota \\ ${ }^{7}$ Hospital Internal Medicine, Division of General \\ Internal Medicine, Mayo Clinic College of Medicine, \\ Rochester, Minnesota \\ ${ }^{8}$ Division of Health Care Policy and Research, \\ Mayo Clinic College of Medicine, Rochester, Min- \\ nesota
}

We thank Donna K. Lawson for her assistance in data collection and management.

Supported by Hospital Medicine Fellowship Program, Mayo Clinic, Rochester, MN.

Presented in part at the American Association of Orthopedic Surgeons Annual Conference, Chicago, Illinois, March 22-26, 2006 and the American Geriatrics Society 2007 Annual Scientific Meeting, Seattle, Washington, May 2-6, 2007.

Accepted for presentation to the American Geriatrics Society 2007 Annual Scientific Meeting, Seattle, Washington, May 2-6, 2007.
BACKGROUND: We previously demonstrated that a hospitalist service created to medically manage patients with hip fracture reduced time to surgery and length of hospital stay, with no difference in inpatient mortality, compared with patients who received standard care. Whether this improved efficiency affects long-term mortality is unknown.

OBJECTIVE: This study examined the effects of this hospitalist service versus standard care on mortality up to 1 year and identified predictors of mortality in patients with hip fracture.

DESIGN: Retrospective cohort study.

SETTING: Tertiary care center.

PATIENTS: Four hundred and sixty-six consecutive patients admitted for surgical repair of a hip fracture in 2000-2002 with 93\% 1-year follow-up.

RESULTS: There was no significant difference in survival of the patients between those on the hospitalist care service and those on the standard care service $(70.5 \%$ [CI: $64.8 \%, 76.7 \%$ ] vs. $70.6 \%$ [CI: $64.9 \%, 76.8 \%$ ]; $P=.36$ ), despite the shortened time to surgery and decreased length of stay in the hospitalist group. Predictors of mortality included: admission from a nursing home (hazard ratio [HR] 2.24, [CI: 1.73, 2.90]); age at admission (HR 1.17 [CI: 0.99, 1.38]); inpatient complications, including ICU admission, myocardial infarction, or acute renal failure (HR 1.85 [CI: 1.45, 2.35]); and ASA class III or IV compared with ASA class II (HR 4.20 [CI: 2.21, 7.99]).

CONCLUSIONS: The improved efficiency in reducing length of stay and time to surgery in the hospitalist group did not adversely affect long-term mortality of this patient population. Journal of Hospital Medicine 2007;2:219-225.

(C) 2007 Society of Hospital Medicine.

KEYWORDS: hospitalist as consultant, geriatric patient, osteoporosis, post-operative evaluation.

D ecause the incidence of hip fracture increases dramatically D with age and the elderly are the fastest-growing portion of the United States population, the number of hip fractures is expected to triple by $2040 .{ }^{1}$ With the associated increase in postoperative morbidity and mortality, the costs will likely exceed $\$ 16-\$ 20$ billion annually. ${ }^{1-5}$ Already by 2002, the number of patients with hip fractures exceeded 340,000 in this country, resulting in $\$ 8.6$ billion in health care expenditures from in-hospital and posthospital costs. $^{6-8}$ This makes hip fracture a serious public health concern and triggers a need to devise an efficient means of caring for these patients. We previously reported that a hospitalist service can decrease time to surgery and shorten length of stay without affecting the number of inpatient deaths or 30-day readmissions of patients undergoing hip fracture surgery. ${ }^{9}$ However, one concern 
with reducing length of stay and time to surgery in the high-risk hip fracture patient population is the effect on long-term mortality because the death rate following hip fracture repair may be as high as $43 \%$ after 1 year. ${ }^{10}$ To evaluate this important issue, we assessed mortality over a 1-year period in the same cohort of patients previously described. ${ }^{9}$ We also identified predictors associated with mortality. We hypothesized that the expedited surgical treatment and decreased length of stay of a hospitalistmanaged group would not have an adverse effect on 1-year mortality.

\section{METHODS}

\section{Patient Selection}

Following approval by the Mayo Clinic Institutional Review Board, we used the Mayo Clinic Surgical Index to identify patients admitted between July 1 , 2000, and June 30, 2002, who matched International Classification of Diseases (9th Edition) hip fracture codes. ${ }^{11}$ These patients were cross-referenced with those having a primary surgical indication of hip fracture. Patients transferred to our facility more than 72 hours after fracture were excluded from our study. Study patients provided authorization to use their medical records for the purposes of research.

A cohort of 466 patients was identified. For purposes of comparison, patients admitted between July 1, 2000, and June 30, 2001, were deemed to belong to the standard care service, and patients admitted between July 1, 2001, and June 30, 2002, were deemed part of the hospitalist service.

\section{Intervention}

Prior to July 2001, Mayo Clinic patients aged 65 and older having surgical repair of a hip fracture were triaged directly to a surgical orthopedic or general medical teaching service. Patients with multiple medical diagnoses were managed initially on a medical teaching service prior to transfer to the operating room. The primary team (medical or surgical) was responsible for the postoperative care of the patient and any orders or consultations required.

After July 1, 2001, these patients were admitted by the orthopedic surgery service and medically comanaged by a hospitalist service, which consisted of a hospitalist physician and 2 allied-health practitioners. Twelve hospitalists and 12 allied health care professionals cared for patients during the study period. All preoperative and postoperative evaluations, inpatient management decisions, and coordination of outpatient care were performed by the hospitalists. This model of care is similar to one previously studied and published elsewhere. ${ }^{12}$ A census cap of 20 patients limited the number of patients managed by the hospitalist service. Any overflow of hip fracture patients was triaged directly to a non-hospitalist-based primary medical or surgical service as before. Thus, 23 hip fracture patients (10\%) admitted after July 1, 2001, were not managed by the hospitalists but are included in this group for an intent-to-treat analysis.

\section{Data Collection}

Study nurses abstracted all data including admitting diagnoses, demographic features, type and mechanism of hip fracture, admission date and time, American Society of Anesthesia (ASA) class, comorbid medical conditions, medications, all clinical data, and readmission rates. Date of last followup was confirmed using the Mayo Clinic medical record, whereas date and cause of death were obtained from death certificates obtained from state and national sources. Length of stay was defined as the number of days between admission and discharge. Time to surgery was defined in hours as the time from hospital admission to the start of the surgery. Finally, time from surgery to dismissal was defined as the number of days from the initiation of the surgical procedure to the time of dismissal. Thirty-day readmission was defined as readmission to our hospital within 30 days of discharge date.

\section{Statistical Considerations Power}

The power analysis was based on the end point of survival following surgical repair of hip fracture and primary comparison of patients in the standard care group with those in the hospitalist group. With 236 patients in the standard care group, 230 in the hospitalist group, and 274 observed deaths during the follow-up period, there was $80 \%$ power to detect a hazard ratio of 1.4 or greater as being statistically significant (alpha $=0.05$, beta $=0.2$ ).

\section{Analysis}

The analysis focused on the end point of survival following surgical repair of hip fracture. In addition to the hospitalist versus standard care service, demographic, baseline clinical, and in-hospital data were evaluated as potential predictors of survival. Survival rates were estimated using the method of Kaplan and Meier, and relative differences in sur- 
vival were evaluated using the Cox proportional hazards regression models. ${ }^{13,14}$ Potential predictors were analyzed both univariately and in a multivariable model. For the multivariable model, initial variable selection was accomplished using stepwise selection, backward elimination, and recursive partitioning. ${ }^{15}$ Each method yielded similar results. Bootstrap resampling was then used to confirm the variables selected for each model. ${ }^{16,17}$ The threshold of statistical significance was set at $P=.05$ for all tests. All analyses were conducted in SAS version 8.2 (SAS Institute Inc., Cary, NC) and Splus version 6.2.1 (Insightful Corporation, Seattle, WA).

\section{RESULTS}

There were 236 patients with hip fractures (50.6\%) admitted to the standard care service, and 230 patients (49.4\%) admitted to the hospitalist service. As shown in Table 1, the baseline characteristics of the patients admitted to the 2 services did not differ significantly except that a greater proportion of patients with hypoxia were admitted to the hospitalist service $(11.3 \%$ vs. $5.5 \%$; $P=.02)$. However, time to surgery, postsurgery stay, and overall length of hospitalization of the hospitalist-treated patients were all significantly shorter.

Patients were followed for a median of 4.0 years (range 5 days to 5.6 years), and 192 patients were still alive at the end of follow-up (April 2006). As illustrated in Figure 1, survival did not differ between the 2 treatment groups $(P=.36)$. Overall survival at 1 year was $70.6 \%$ (95\% confidence interval $[\mathrm{CI}]: 66.5 \%, 74.9 \%)$. Survival at 1 year in the standard care group was $70.6 \%$ (95\% CI: $64.9 \%$, $76.8 \%)$, whereas in the hospitalist group, it was $70.5 \%$ (95\% CI: $64.8 \%, 76.7 \%$ ). As delineated in Table 2, cardiovascular causes accounted for 34 deaths $(25.6 \%)$, with 14 of these in the standard care group and 20 in the hospitalist group; 29 deaths (21.8\%) had respiratory causes, 20 in the standard care group and 9 in the hospitalist group; and 17 (12.8\%) were due to cancer, with 7 and 10 in the standard care and hospitalist groups, respectively. Unknown causes accounted for 21 cases, or $15.8 \%$ of total deaths.

In the univariate analysis, we found 29 variables that were significant predictors of survival (Table 3 ). A hospitalist model of care was not significantly associated with patient survival, despite the shorter length of stay (8.4 days vs. 10.6 days; $P<.001$ ) or expedited time to surgery (25 vs. 38 hours; $P$ $<.001$ ), when compared with the standard care group, as previously reported by Phy et al. ${ }^{9}$ In the multivariable analysis (Table 4), however, the independent predictors of mortality were ASA class III or IV versus class II (hazard ratio [HR] 4.20; 95\% CI: $2.21,7.99$ ), admission from a nursing home versus from home or assisted living (HR 2.24; 95\% CI: 1.73, 2.90), and inpatient complications, which included patients requiring admission to the intensive care unit (ICU) and those who had a myocardial infarction or acute renal failure as an inpatient (HR 1.85; 95\% CI: 1.45, 2.35). Even after adjusting for these factors, survival following hip fracture did not differ significantly between the hospitalist care patients and the standard care patients (HR 1.16; 95\% CI: $0.91,1.48)$.

\section{DISCUSSION}

In our previous study, length of stay and time to surgery were significantly lower in a hospitalist care model. ${ }^{9}$ The present study shows that neither the reduced length of stay nor the shortened time to surgery of patients managed by the hospitalist group was associated with a difference in mortality compared with a standard care group, despite significantly improved efficiency and processes of care. Thus, our results refute initial concerns of increased mortality in a hospitalist model of care.

Delivery of perioperative medical care to hip fracture patients by hospitalists is associated with significant decreases in time to surgery and length of stay compared with standard care, with no differences in short-term mortality. ${ }^{9,18}$ Although there have been conflicting reports on the impact of length of stay and time to surgery on long-term outcomes, our findings support previous results that decreased time to surgery was not associated with an observable effect on mortality. ${ }^{19-23 .}$ A recent study by Orosz et al. that evaluated 1178 patients showed that earlier hip fracture surgery (performed less than 24 hours after admission) was not associated with reduced mortality, although it was associated with shorter length of stay. ${ }^{19}$ Our study also corroborates the results of an examination of 8383 hip fracture patients by Grimes et al., who found that time to surgery between 24 and 48 hours after admission had no effect on either 30-day or longterm mortality compared with that of those who underwent surgery between 48 and 72 hours, between 72 and 96 hours, or more than 96 hours after admission. ${ }^{20}$ However, both these results and our own are contrary to those of Gdalevich, whose study of 651 patients found that 1-year mortality 
TABLE 1

Characteristics of 466 Hip Fracture Patients at Time of Admission

\begin{tabular}{|c|c|c|c|c|c|}
\hline \multirow{2}{*}{$\begin{array}{l}\text { Patient characteristic } \\
\text { Age (years) }\end{array}$} & \multicolumn{2}{|c|}{$\begin{array}{l}\text { Standard care } \\
n=236\end{array}$} & \multicolumn{2}{|c|}{$\begin{array}{l}\text { Hospitalist care } \\
n=230\end{array}$} & \multirow{2}{*}{$\begin{array}{c}P \text { value } \\
.34\end{array}$} \\
\hline & 82 & & 83 & & \\
\hline Female sex & 171 & $72.5 \%$ & 163 & $70.9 \%$ & .70 \\
\hline \multicolumn{6}{|l|}{ Comorbidity } \\
\hline Coronary artery disease & 69 & $29.2 \%$ & 77 & $33.5 \%$ & .32 \\
\hline Congestive heart failure & 41 & $17.4 \%$ & 49 & $21.3 \%$ & .28 \\
\hline Chronic obstructive pulmonary disease & 36 & $15.3 \%$ & 38 & $16.5 \%$ & .71 \\
\hline Cerebral vascular accident or transient ischemic attack & 36 & $15.3 \%$ & 50 & $21.7 \%$ & .07 \\
\hline Dementia & 54 & $22.9 \%$ & 62 & $27.0 \%$ & .31 \\
\hline Diabetes & 45 & $19.1 \%$ & 46 & $20.0 \%$ & .80 \\
\hline Renal insufficiency & 17 & $7.2 \%$ & 17 & $7.4 \%$ & .94 \\
\hline Residence at time of admission & & & & & .07 \\
\hline Home & 149 & $63.1 \%$ & 138 & $60.0 \%$ & \\
\hline Assisted living & 32 & $13.6 \%$ & 42 & $18.3 \%$ & \\
\hline Nursing home & 55 & $23.3 \%$ & 50 & $21.7 \%$ & \\
\hline Ambulatory status at time of admission & & & & & .14 \\
\hline Independent & 114 & $48.3 \%$ & 89 & $38.7 \%$ & \\
\hline Assistive device & 99 & $41.9 \%$ & 115 & $50.0 \%$ & \\
\hline Personal help & 9 & $3.8 \%$ & 16 & $7.0 \%$ & \\
\hline Transfer to bed or chair & 9 & $3.8 \%$ & 7 & $3.0 \%$ & \\
\hline Nonambulatory & 5 & $2.1 \%$ & 3 & $1.3 \%$ & \\
\hline \multicolumn{6}{|l|}{ Signs at time of admission } \\
\hline Hypotension & 4 & $1.7 \%$ & 3 & $1.3 \%$ & $>.99$ \\
\hline Hypoxia & 13 & $5.5 \%$ & 26 & $11.3 \%$ & .02 \\
\hline Pulmonary edema & 37 & $15.7 \%$ & 29 & $12.6 \%$ & .34 \\
\hline Tachycardia & 19 & $8.1 \%$ & 25 & $10.9 \%$ & .3 \\
\hline Fracture type & & & & & .78 \\
\hline Femoral neck & 118 & $50.0 \%$ & 118 & $51.3 \%$ & \\
\hline Intertrochanteric & 118 & $50.0 \%$ & 112 & $48.7 \%$ & \\
\hline Mechanism of fracture & & & & & .82 \\
\hline Fall & 219 & $92.8 \%$ & 212 & $92.2 \%$ & \\
\hline Trauma & 1 & $0.4 \%$ & 3 & $1.3 \%$ & \\
\hline Pathologic & 7 & $3.0 \%$ & 6 & $2.6 \%$ & \\
\hline Unknown & 9 & $3.8 \%$ & 7 & $3.0 \%$ & \\
\hline $\mathrm{ASA}^{*}$ class & & & & & .38 \\
\hline I or II & 33 & $14.0 \%$ & 23 & $10.0 \%$ & \\
\hline III & 166 & $70.3 \%$ & 166 & $72.2 \%$ & \\
\hline IV & 37 & $15.7 \%$ & 41 & $17.8 \%$ & \\
\hline Location discharged to ${ }^{\dagger}$ & & & & & .07 \\
\hline Home or assisted living & 24 & $10.5 \%$ & 13 & $5.9 \%$ & \\
\hline Nursing home & 196 & $86.0 \%$ & 192 & $87.3 \%$ & \\
\hline Another hospital or hospice & 8 & $3.5 \%$ & 15 & $6.8 \%$ & \\
\hline Time to surgery (hours) & 38 & & 25 & & .001 \\
\hline Time from surgery to discharge (days) & 9 & & 7 & & .04 \\
\hline Length of stay & 10.6 & & 8.4 & & $<.00$ \\
\hline Readmission rate & 25 & $10.6 \%$ & 20 & $8.7 \%$ & .49 \\
\hline
\end{tabular}

*American Society of Anesthesia.

${ }^{\dagger} 18$ Inpatient deaths were excluded.

From Phy MP, Vanness DJ, Melton LJ 3rd, et al. Effects of a hospitalist care model on elderly patients with hip fractures. Arch Intern Med. 2005;165:796-801. Permission obtained from American Medical Association/ Copyright ${ }^{\circ} 2005$. All rights reserved. 


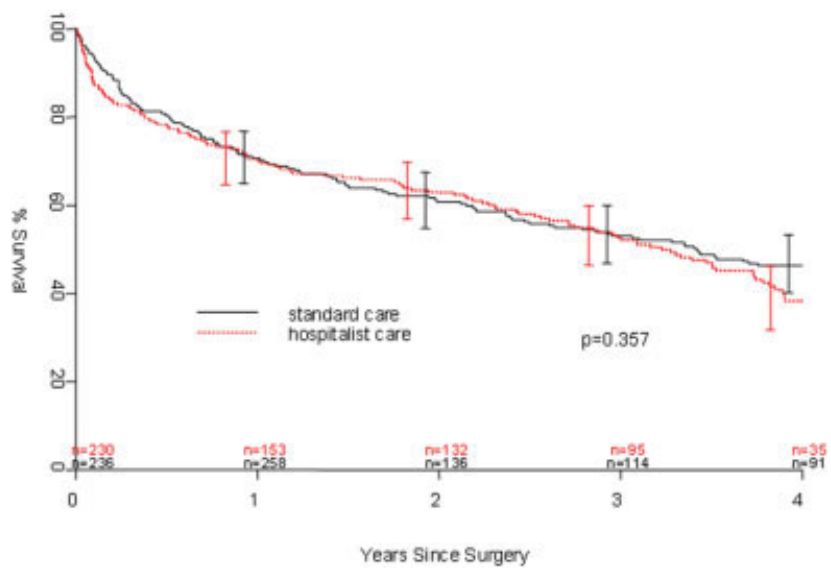

FIGURE 1. Survival following original hip fracture repair of 230 patients receiving hospitalist care and 236 patients receiving standard care. [Color figure can be viewed in the online issue, which is available at www. interscience.wiley.com]

TABLE 2

Certified Underlying Cause of Death as Recorded on Death Certificates after 1 Year of Following Patients with Hip Fractures

\begin{tabular}{lcccc}
\hline & Standard care & Hospitalist care & Total No. of deaths & $\%$ \\
\hline Cancer & 7 & 10 & 17 & $12.8 \%$ \\
Cardiovascular & 14 & 20 & 34 & $25.6 \%$ \\
Infectious & 5 & 4 & 9 & $6.8 \%$ \\
Neurological & 5 & 10 & 15 & $11.3 \%$ \\
Other & 0 & 2 & 2 & $1.5 \%$ \\
Renal & 4 & 2 & 6 & $4.5 \%$ \\
Respiratory & 20 & 9 & 29 & $21.8 \%$ \\
Unknown & 11 & 10 & 21 & $15.8 \%$ \\
Total & 66 & 67 & 133 & $100.0 \%$ \\
\hline
\end{tabular}

was 1.6-fold higher for those whose hip fracture repair was postponed more than 48 hours. ${ }^{21}$ However, time to surgery in both the standard care and hospitalist model in our study was well below the 48-hour cutoff, suggesting that operating anywhere within the normally accepted 48-hour time frame may not influence long-term mortality.

Because of the small number of events in both groups, we were unable to specifically compare whether a hospitalist model of care has any specific impact on long-term cause of death. Although causes of death of patients with hip fracture were consistent with those of previous studies, ${ }^{10,24}$ our death rate at 1 year, $29.4 \%$, was higher than that seen among similar population groups at tertiary referral centers. ${ }^{19,20,24-29}$ This is most likely a result of the cohort having a high proportion of nursing home patients $(22 \%)^{19,24,26}$ transferred for evalua-
TABLE 3

Univariate Predictors of Mortality 1 year after Surgical Repair of Hip Fracture

\begin{tabular}{|c|c|c|}
\hline Variable & Hazard ratio $\left(95 \% \mathrm{CI}^{\dagger}\right)$ & $P$ value \\
\hline Age on admission per 10 years & $1.41(1.20,1.65)$ & $<.001$ \\
\hline $\mathrm{ASA}^{*} \mathrm{II}$ & 1.0 (referent) & \\
\hline ASA* III & $5.27(2.79,9.96)$ & $<.001$ \\
\hline $\mathrm{ASA}^{*} \mathrm{IV}$ & $11.7(5.97,22.9)$ & $<.001$ \\
\hline \multicolumn{3}{|c|}{ History of chronic obstructive pulmonary } \\
\hline disease & $1.82(1.35,2.43)$ & $<.001$ \\
\hline History of renal insufficiency & $2.40(1.62,3.55)$ & $<.001$ \\
\hline \multicolumn{3}{|l|}{ History of stroke/transient ischemic } \\
\hline History of diabetes & $1.70(1.29,2.25)$ & $<.001$ \\
\hline History of congestive heart failure & $2.26(1.73,2.96)$ & $<.001$ \\
\hline History of coronary artery disease & $1.53(1.20,1.97)$ & $<.001$ \\
\hline History of dementia & $2.02(1.57,2.59)$ & $<.001$ \\
\hline Admission from home & 1.0 (referent) & \\
\hline Admission from assisted living & $1.47(1.06,2.04)$ & .02 \\
\hline Admission from nursing home & $3.04(2.33,3.98)$ & $<.001$ \\
\hline Independent & 1.0 (referent) & \\
\hline Use of assistive device & $1.81(1.39,2.36)$ & $<.001$ \\
\hline Personal help & $3.49(2.16,5.64)$ & $<.001$ \\
\hline Nonambulatory & $3.96(2.47,6.35)$ & $<.001$ \\
\hline Crackles on admission & $2.03(1.50,2.74)$ & $<.001$ \\
\hline Hypoxia on admission & $1.56(1.04,2.32)$ & .03 \\
\hline Hypotension on admission & $6.21(2.72,14.2)$ & $<.001$ \\
\hline Tachycardia on admission & $1.66(1.15,2.41)$ & .007 \\
\hline Coumadin on admission & $1.57(1.13,2.18)$ & .007 \\
\hline \multicolumn{3}{|l|}{ Confusion/unconsciousness on } \\
\hline Fever on admission & $1.98(1.16,3.40)$ & .01 \\
\hline Tachypnea on admission & $1.95(1.39,2.72)$ & $<.001$ \\
\hline Inpatient myocardial Infarction & $3.59(2.35,5.48)$ & $<.001$ \\
\hline Inpatient atrial fibrillation & $2.00(1.37,2.92)$ & $<.001$ \\
\hline Inpatient congestive heart failure & $2.62(1.79,3.84)$ & $<.0001$ \\
\hline Inpatient delirium & $1.46(1.13,1.90)$ & $<.005$ \\
\hline Inpatient lung infection & $2.52(1.85,3.42)$ & $<.001$ \\
\hline Inpatient respiratory failure & $2.76(1.64,4.66)$ & $<.001$ \\
\hline Inpatient mechanical ventilation & $2.56(1.43,4.57)$ & .002 \\
\hline Inpatient renal failure & $3.60(1.97,6.61)$ & $<.001$ \\
\hline Days from admission to surgery & $1.06(1.005,1.12)$ & .03 \\
\hline Intensive care unit stay & $1.93(1.51,2.47)$ & $<.001$ \\
\hline
\end{tabular}

${ }^{*}$ American Society of Anesthesia; ${ }^{\dagger}$ confidence interval.

tion to St. Mary's Hospital, which serves most of Olmsted County, Minnesota. This hospital also has some characteristics of a community-based hospital, as it is where greater than $95 \%$ of all county patients receive care for surgical repair of hip fracture. Mortality rates are often higher at these types of hospitals. ${ }^{30}$ Previous studies using patients from Olmsted County indicate results can also be extrapolated to a large part of the U.S. population. ${ }^{31}$ In Pitto et al.'s study, the risk of death was $31 \%$ lower in those admitted from home than for those admit- 
TABLE 4

Multivariable Predictors of Survival Following Surgical Repair of Hip Fracture

\begin{tabular}{|c|c|c|}
\hline Variable & Hazard ratio $\left(95 \% \mathrm{CI}^{\dagger}\right)$ & $P$ value \\
\hline Age on admission per 10 years & $1.17(0.99,1.38)$ & .07 \\
\hline ASA $^{*}$ class III or IV & $4.20(2.21,7.99)$ & $<.001$ \\
\hline ASA $^{*}$ class II & 1.0 (referent) & \\
\hline Admission from nursing home & $2.24(1.73,2.90)$ & $<.001$ \\
\hline Admission from home or assisted living & 1.0 (referent) & \\
\hline $\begin{array}{l}\text { Inpatient myocardial infarction, } \\
\text { inpatient acute renal failure, or } \\
\text { intensive care unit stay }\end{array}$ & $1.85(1.45,2.35)$ & $<.001$ \\
\hline $\begin{array}{l}\text { No inpatient myocardial infarction, no } \\
\text { inpatient acute renal failure, and no } \\
\text { intensive care unit stay }\end{array}$ & 1.0 (referent) & \\
\hline
\end{tabular}

ted from a nursing home. ${ }^{32}$ The latter patients normally have a higher number of comorbid conditions and tend to be less ambulatory than those in a community home-dwelling setting. Our study also demonstrated that admission from a nursing home was a strong predictor of mortality for up to 1 year in the geriatric population. This may reflect the inherent decreased survival in this patient group, which is in agreement with the findings of other studies that showed inactivity and decreased ambulation prior to fracture were associated with increased mortality. ${ }^{33-35}$

Multiple comorbidities, commonly seen in a geriatric population, translate into a higher ASA class and an increased risk of significant in-hospital complications. Our study confirmed the findings of previous studies that a higher ASA class is a strong predictor of mortality, ${ }^{21,26,30,35-37}$ independent of decreased time to surgery. ${ }^{38}$ We also noted that significant in-hospital complications, including renal failure, respiratory failure, and myocardial infarction, are documented predictors of mortality after hip fracture. ${ }^{27}$ Although mortality may vary depending on fracture type (femoral neck vs. intertrochanteric), ${ }^{39-41}$ these differences were not observed in our study, in line with the results of previous published studies. ${ }^{37,42}$ Controlling for age and comorbidities may be why an association was not found between fracture type and mortality. Finally, in a model containing comorbidity, ASA class, and nursing home residence prior to fracture, age was not a significant predictor of mortality.

Our study had a number of limitations. First, this was a retrospective cohort study based on chart review, so some data may have been subject to recording bias, and this might have differed between the serial models. Because of the retrospective nature of the study and referral of some of the patients from outside the community, our 1-year follow-up was not complete, but approached a respectable 93\%. Other studies have described the benefits derived by a hospitalist practice only following the first year of its implementation, likely because of the hospitalist learning curve. ${ }^{43,44}$ This may be why there was no difference in mortality between the standard care and hospitalist groups, as the latter was only in its first year of existence. Additional longitudinal study is required to find out if mortality differences emerge between the treatment groups. Furthermore, although in-hospital care may influence short-term outcomes, its effect on long-term mortality has been unclear. Our data demonstrate that even though a hospitalist service can shorten length of stay and time to surgery, there were no appreciable intermediate differences in mortality at 1 year. Further prospective studies are needed to determine whether this medical-surgical partnership in caring for these patients provides more favorable outcomes of reducing mortality and intercurrent complications.

Address for correspondence and reprint requests: Dr. Jeanne M. Huddleston, Assistant Professor of Medicine, Mayo Clinic College of Medicine, Hospital Internal Medicine, Department of Medicine, Rochester, MN 55905; Fax: (507) 255-1027; E-mail: huddleston.jeanne@mayo.edu

Received 24 November 2006; revision received 2 February 2007; accepted 28 February 2007.

\section{REFERENCES}

1. Cummings SR, Rubin SM, Black D. The future of hip fractures in the United States. Numbers, costs, and potential effects of postmenopausal estrogen. Clin Orthop Relat Res 1990(252):163-166.

2. Cooper C, Campion G, Melton LJ 3rd. Hip fractures in the elderly: a world-wide projection. Osteoporos Int. 1992;2:285289.

3. Haentjens P, Autier P, Barette M, Boonen S. The economic cost of hip fractures among elderly women. A one-year, prospective, observational cohort study with matched-pair analysis. Belgian Hip Fracture Study Group. J Bone Joint Surg Am. 2001;83-A:493-500.

4. Braithwaite RS, Col NF, Wong JB. Estimating hip fracture morbidity, mortality and costs. J Am Geriatr Soc. 2003;51: 364-370.

5. Schneider EL, Guralnik JM. The aging of America. Impact on health care costs. JAMA. 1990;263:2335-2340.

6. Ray NF, Chan JK, Thamer M, Melton LJ 3rd. Medical expenditures for the treatment of osteoporotic fractures in the United States in 1995: report from the National Osteoporosis Foundation. J Bone Miner Res. 1997;12(1):24-35. 
7. US Department of Health and Human Services. Surveillance for selected public health indicators affecting older adults —United States. MMWR Morb Mortal Wkly Rep 1999;48:3334.

8. Cummings SR, Melton LJ 3rd. Epidemiology and outcomes of osteoporotic fractures. Lancet. 2002;359:1761-1767.

9. Phy MP, Vanness DJ, Melton LJ 3rd, et al. Effects of a hospitalist model on elderly patients with hip fracture. Arch Intern Med. 2005;165:796-801.

10. Heikkinen T, Parker M, Jalovaara P. Hip fractures in Finland and Great Britain-a comparison of patient characteristics and outcomes. Int Orthop. 2001;25:349-354.

11. WHO. International Classification of Disease, Ninth Revision (ICD-9). Geneva, Switzerland: World Health Organization; 1977.

12. Huddleston JM, Long KH, Naessens JM, et al. Medical and surgical comanagement after elective hip and knee arthroplasty: a randomized, controlled trial. Ann Intern Med. 2004; 141(1):28-38.

13. Cox D. Regression models and life-tables (with discussion). J R Stat Soc Ser B. 1972;34:187-220.

14. Kaplan E, Meier P. Nonparametric estimation from incomplete observations. J Am Statistical Assoc. 1958;53:457-481.

15. Therneau TM, Atkinson E. An Introduction to Recursive Partitioning using the RPART Routines: Section of Biostatistics, Mayo Clinic; 1997.

16. Urban H. Computer Intensive Statistical Methods, Validation, Model Selection, and Bootstrap. London: Chapman and Hall; 1994.

17. Sauerbrei W, Schumacher M. A bootstrap resampling procedure for model building: application to the Cox regression model. Stat Med. 1992;11:2093-2109.

18. Roy A, Heckman MG, Roy V. Associations between the hospitalist model of care and quality-of-care-related outcomes in patients undergoing hip fracture surgery. Mayo Clin Proc. 2006;81(1):28-31.

19. Orosz GM, Magaziner J, Hannan EL, et al. Association of timing of surgery for hip fracture and patient outcomes. JAMA. 2004;291:1738-1743.

20. Grimes JP, Gregory PM, Noveck H, Butler MS, Carson JL. The effects of time-to-surgery on mortality and morbidity in patients following hip fracture. Am J Med. 2002;112:702-709.

21. Gdalevich M, Cohen D, Yosef D, Tauber C. Morbidity and mortality after hip fracture: the impact of operative delay. Arch Orthop Trauma Surg. 2004;124:334-340.

22. Siegmeth AW, Gurusamy K, Parker MJ. Delay to surgery prolongs hospital stay in patients with fractures of the proximal femur. J Bone Joint Surg Br. 2005;87:1123-1126.

23. Parker MJ, Pryor GA. The timing of surgery for proximal femoral fractures. J Bone Joint Surg Br. 1992;74(2):203-205.

24. Boockvar KS, Halm EA, Litke A, et al. Hospital readmissions after hospital discharge for hip fracture: surgical and nonsurgical causes and effect on outcomes. J Am Geriatr Soc. 2003;51:399-403.

25. Jensen JS, Tondevold E. Mortality after hip fractures. Acta Orthop Scand 1979;50(2):161-167.

26. Lawrence VA, Hilsenbeck SG, Noveck H, Poses RM, Carson JL. Medical complications and outcomes after hip fracture repair. Arch Intern Med. 2002;162:2053-2057.
27. Jiang HX, Majumdar SR, Dick DA, et al. Development and initial validation of a risk score for predicting in-hospital and 1-year mortality in patients with hip fractures. $J$ Bone Miner Res. 2005;20:494-500.

28. Shah MR, Aharonoff GB, Wolinsky P, Zuckerman JD, Koval KJ. Outcome after hip fracture in individuals ninety years of age and older. J Orthop Trauma. 2001;15(1):34-39.

29. Aharonoff GB, Koval KJ, Skovron ML, Zuckerman JD. Hip fractures in the elderly: predictors of one year mortality. J Orthop Trauma. 1997;11(3):162-165.

30. Weller I, Wai EK, Jaglal S, Kreder HJ. The effect of hospital type and surgical delay on mortality after surgery for hip fracture. J Bone Joint Surg Br. 2005;87:361-366.

31. Melton LJ 3rd. History of the Rochester Epidemiology Project. Mayo Clin Proc. 1996;71:266-274.

32. Pitto RP. The mortality and social prognosis of hip fractures. A prospective multifactorial study. Int Orthop. 1994;18(2): 109-113.

33. Rosell PA, Parker MJ. Functional outcome after hip fracture. A 1-year prospective outcome study of 275 patients. Injury. 2003;34:529-532.

34. White BL, Fisher WD, Laurin CA. Rate of mortality for elderly patients after fracture of the hip in the 1980's. J Bone Joint Surg Am. 1987;69:1335-1340.

35. Broos PL, Van Haaften KI, Stappaerts KH, Gruwez JA. Hip fractures in the elderly. Mortality, functional results and social readaptation. Int Surg. 1989;74(3):191-194.

36. Swain DG, Nightingale PG, Patel JV. Blood transfusion requirements in femoral neck fracture. Injury. 2000;31(1):7-10.

37. Boereboom FT, Raymakers JA, Duursma SA. Mortality and causes of death after hip fractures in The Netherlands. Neth J Med. 1992;41(1-2):4-10.

38. Stoddart J, Horne G, Devane P. Influence of preoperative medical status and delay to surgery on death following a hip fracture. ANZ J Surg. 2002;72:405-407.

39. Marottoli RA, Berkman LF, Leo-Summers L, Cooney LM Jr. Predictors of mortality and institutionalization after hip fracture: the New Haven EPESE cohort. Established Populations for Epidemiologic Studies of the Elderly. Am J Public Health. 1994;84:1807-1812.

40. Richmond J, Aharonoff GB, Zuckerman JD, Koval KJ. Mortality risk after hip fracture. J Orthop Trauma. 2003;17(1):5356.

41. Parvizi J, Ereth MH, Lewallen DG. Thirty-day mortality following hip arthroplasty for acute fracture. J Bone Joint Surg Am. 2004;86-A:1983-1988.

42. Cornwall R, Gilbert MS, Koval KJ, Strauss E, Siu AL. Functional outcomes and mortality vary among different types of hip fractures: a function of patient characteristics. Clin Orthop Relat Res. 2004:64-71.

43. Auerbach AD, Wachter RM, Katz P, Showstack J, Baron RB, Goldman L. Implementation of a voluntary hospitalist service at a community teaching hospital: improved clinical efficiency and patient outcomes. Ann Intern Med. 2002;137: 859-865

44. Meltzer D, Manning WG, Morrison J, et al. Effects of physician experience on costs and outcomes on an academic general medicine service: results of a trial of hospitalists. Ann Intern Med. 2002;137:866-874. 